\title{
Perception of Clinical Training and Future Objectives of Residents of Oral Implantology (POCTOIR-30 Questionnaire): A Pilot Study of Statistical Validation
}

\author{
Frank Mayta-Tovalino ${ }^{1}$, G Mendoza-Azpur ${ }^{2}$, Yens Mendoza-Martiarena ${ }^{3}$, María Álvarez-Paucar ${ }^{4}$, Luis Gálvez-Calla ${ }^{5}$ \\ Luz Carbajal ${ }^{6}$
}

\begin{abstract}
Aim: The aim of the present study was to develop and validate the psychometric properties of the questionnaire (POCTOIR-30) for the evaluation of the perception of clinical training and future goals of residents of oral implantology.

Materials and methods: The development of the questionnaire followed the process of five phases: (a) preparation of the instrument, (b) validation of the content, (c) validity of the construct, (d) evaluation of internal consistency and reliability, (e) evaluation of the level of knowledge, for which an instrument on implant training of residency programs was used as a reference. To evaluate the sensitivity and validity of the questionnaire, a pilot sample of 20 residents between 20 years and 50 years of a residency program in oral implantology was used.

Results: The factor analysis of the data and the adjustment statistics process resulted in the quality care of 4 factors and 30 questions that were included in the present questionnaire (POCTOIR), which covers: logistics and infrastructure (five items), training in oral implantology (10 items); information on the postgraduate program (seven items) and accessibility and sustainability of care (ten items) and future goals after postgraduate studies (five items). Content validity was measured using the index that combines the ease of calculation and the evaluation of results at the statistical level $(\kappa$ 0.833). The reliability of the instrument was evaluated to measure the degree of internal correlation (Cronbach's $\alpha 0.738)$. Finally, the reliability was evaluated to measure the constancy of the responses repeatedly with the same subjects (intraclass correlation 0.74). Conclusion: This study showed that the POCTOIR-30 instrument has adequate levels of validity and reliability to be used in residents of areas related to oral implantology in new research.

Clinical significance: The impact of the academic training of the residents in oral implantology significantly influences their performance at the time of performing the surgical and prosthetic protocols. Therefore, this research validates statistically the perception of academic training and future goals of postgraduate residents in order to quantify and apply improvement strategies during their years of study.

Keywords: Aptitude tests, Oral implantology, Questionnaire, Resident program, Validation.

World Journal of Dentistry (2019): 10.5005/jp-journals-10015-1645
\end{abstract}

\section{INTRODUCTION}

Since the beginning of 2007, we have seen the need to incorporate oral implantology into the postgraduate educational model in the Peruvian stomatology. In this way, the guidelines that agree to introduce it as a specialty in Peru are followed. However, the approaches have varied and have not been standardized, for what there are reports in the last decade that have demonstrated that many faculties of dentistry have incorporated to the oral implantology in their plans of study, although there is a lack of practical experience, use of models, as well as clinical practice. ${ }^{1-8}$ Currently, the treatment with dental implants is highly predictable and offers restoration options valid for the totally or partially edentulous patient. In many countries, this treatment has already been incorporated. For example, many patients receive dental implant treatment in the dentistry schools at both undergraduate and postgraduate levels. The approach to implant education varies by country and university, in some cases the majority of students have not received a systematic education in implant treatment. Therefore, it is very common for graduate dentists to have learned the information and techniques about implants through workshops and conferences that provide basic knowledge. Thus, the systematic curriculum is necessary in implant education so that postgraduate students can better understand the globalization of dental implant treatment. ${ }^{9-14}$

\footnotetext{
1,2 Postgraduate Department in Periodontology, Faculty of Stomatology, Universidad Científica del Sur, Lima, Peru

${ }^{3-5}$ Academic Department, School of Dentistry, Universidad Nacional Mayor de San Marcos, Lima, Peru

${ }^{6}$ Department of Statistics and Demography, Faculty of Science and Philosophy, Universidad Peruana Cayetano Heredia, Lima Peru
}

Corresponding Author: Frank Mayta-Tovalino, Postgraduate Department in Periodontology, Faculty of Stomatology, Universidad Científica del Sur, Lima, Peru, Phone: +51 1 214-2500, e-mail:fmaytat@ucientifica. edu.pe

How to cite this article: Mayta-Tovalino F, Mendoza-Azpur G, MendozaMartiarena Y, et al. Perception of Clinical Training and Future Objectives of Residents of Oral Implantology (POCTOIR-30 Questionnaire): A Pilot Study of Statistical Validation. World J Dent 2019;10(4):253-258.

Source of support: Nil

Conflict of interest: None

Many studies have evaluated the curricula on the impact that the inclusion of oral implantology has on the undergraduate and postgraduate programs. ${ }^{2,12}$ The most recent studies suggest that it is important to include the course of oral implantology in the evaluated study plans. ${ }^{2,6}$ Most dental schools allow predoctoral

(-) The Author(s). 2019 Open Access This article is distributed under the terms of the Creative Commons Attribution 4.0International License (https://creativecommons. org/licenses/by-nc/4.0/), which permits unrestricted use, distribution, and non-commercial reproduction in any medium, provided you give appropriate credit to the original author(s) and the source, provide a link to the Creative Commons license, and indicate if changes were made. The Creative Commons Public Domain Dedication waiver (http://creativecommons.org/publicdomain/zero/1.0/) applies to the data made available in this article, unless otherwise stated. 
students to perform prosthetic restorations on previously osseointegrated dental implants, ${ }^{8,9,13,15}$ but few offer students the possibility of implant surgery. ${ }^{11,15}$ In this way, the need to offer surgical training for implant placement is increasing and should be addressed in current curricula for students. However, there is little evidence that the curricula of oral implantology have been evaluated for advanced specialty programs. ${ }^{16-18}$

On the other hand, there is little evidence and there are no published studies that have evaluated the surgical formation of implants from the point of view of the residents of a postgraduate program in Peru, since they will be the future professionals that will be developed in community service.

Therefore, the purpose of this pilot study was to develop and validate the questionnaire (POCTOIR-30) for the evaluation of the perception of clinical training and future goals in oral implantology residents.

\section{Materials and Methods}

\section{Study Design}

A cross-sectional study was performed. The POCTOIR-30 questionnaire includes five stages of development: (1) preparation of the instrument, (2) validation of the content, (3) validity of the construct, (4) evaluation of the reliability, and (5) evaluation of the level of knowledge, however, between each step some previous analyzes were made (Flowchart 1). The study was approved by the UPCH ethics committee with code SIDISI 62713. The participants signed the informed consent, while the recruitment requirements were given according to the inclusion criteria: residents of legal age; resident of the post-degree in oral implantology, periodontics, and oral rehabilitation; and residents entering exclusively 2 years before, residents of the headquarters where the study is carried out. Exclusion criteria: residents who do not wish to sign informed consent, residents who belong to other approaches unrelated to the treatment of dental implants.

\section{Phase I: Making the Instrument}

In this phase, an original questionnaire was created, which was assigned the name POCTOIR-30 (perception of clinical training

Flowchart 1: Flowchart of the POCTOIR-30 instrument development

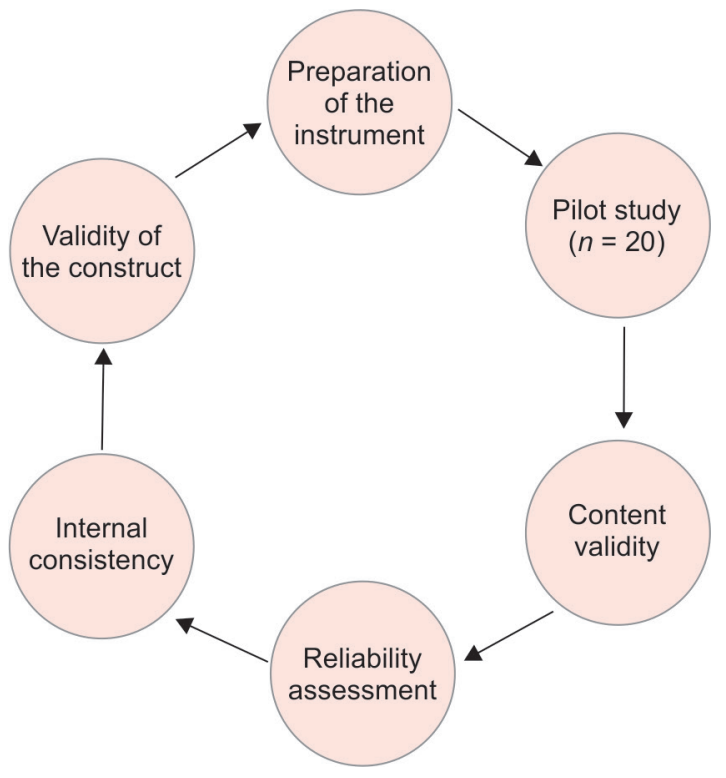

and future goals in oral implantology residents), which will consist of two sections: general data and questions, which have been prepared taking as in reference to an instrument on implant training of the residency programs in maxillofacial surgery in the United States; a questionnaire was designed based on the Melo et al. questionnaire. ${ }^{16}$ The questionnaire had 30 multiple choice questions, where the subjective and objective aspects of the perception about the current training and future goals in oral implantology of the residents of periodontics, oral implantology, and oral rehabilitation were evaluated. A pilot study was carried out to determine the validation, understanding of the instructions, detecting ambiguous or difficult-to-understand items of the instrument. The pilot sample consisted of 20 postgraduate residents in periodontics, oral implantology, and oral rehabilitation, whose ages were between 20 years and 50 years for the subsequent reception of difficulties and suggestions with the purpose of an adequate understanding of the instrument, being this favorable for your application.

\section{Phase II: Validation of Content}

The validity of the questionnaire (POCTOIR-30) will be verified by an expert judgment that included the participation of 8 specialists in oral implantology, periodontics, and rehabilitation, a graduate in statistics and an expert in research methodology with certified experience. Each expert was asked to evaluate the suitability, clarity, relevance of each of the questions, relationship with the problem of the study, vocabulary, appropriate terminology, and verification of the sequence of each of the questions of the proposed questionnaire. The acceptance or objection of the questions will be registered as (1) or (0) respectively with a term of 7 days and the recommendations issued will be evaluated with the redesign of the questions according to the suggestions for its second review and subsequent analysis through the test of Cohen's $\kappa$.

\section{Phase III: Evaluation of Internal Consistency and Reliability}

In this phase, the Cronbach's $\alpha$ test was carried out to evaluate the reliability of the questions, considering values higher than 0.7 as the minimum acceptable criterion to ensure an appropriate internal consistency. To determine the reliability of the questionnaire or testretest reliability, a test was performed in which the questionnaire was provided to the subjects who met the selection criteria. After two weeks, the questionnaire was given to the individuals who participated in the test (retest), to then calculate the intraclass correlation coefficient, where the correlation between each question was analyzed and the scale was included in that question, estimating the convergent validity of the POCTOIR-30 questions.

\section{Phase IV: Validity of the Construct}

This study used factor analysis to analyze construct validity, and performed a multistep scaling analysis to examine to what extent the POCTOIR-30 questions could be combined into a more controlled set of multiple elements. By validation, according to the factorial analysis, the number of questions is established and in how many dimensions should be grouped, leaving a total of 30 questions, grouped into 4 dimensions that the respondents must complete for the validation process.

\section{Phase V: Evaluation of the Level of Perception}

The residents received a detailed and personal explanation of the objectives and justification of the study, prior to entering their class 
hours in the respective services of implantology, periodontics, and rehabilitation. The resident was then given informed consent for his reading, analysis, and signature. Finally, he was handed in a sealed envelope, the instrument, a pen, and was informed that he had an estimated time of 20 minutes to answer the questionnaire. For their analysis, a score was assigned to each answer, the level of knowledge, and attitudes was determined according to the quotient obtained from the division between the number of correct answers and the total number of questions, being the value obtained assigned within the following scales: excellent: $>0.8$; acceptable: $<0.79$ and $>0.6$; regular: $<0.59$ and $>0.4$; deficient: $<0.39$ and $>0.2$; poor: $<0.2$.

\section{Statistical Analysis}

For statistical analysis during the validation process of the questionnaire, we used: for content validity (Cohen's $\kappa$ ), for criterion validity (intraclass correlation coefficient), and for the validity of the construct (factor analysis). For the univariate analysis, we will proceed to obtain the descriptive statistics (mean and standard deviation) of the quantitative variables under study, recorded in a frequency table. In addition, it will be determined if the sample will have normal distribution through the Shapiro-Wilk test. All statistical analysis was performed using the Stata ${ }^{\circledR} 12.0$ software.

\section{Results}

It was established through the judgment of experts who had the degree of teacher, doctor, or specialist, with a background and certified experience in the professional field, who evaluate the degree to which the questions agree with the approaches of the creator of the instrument, whose technique denominates criteria of judges. Therefore, to evaluate the validity of content by criteria of judges, we used the $\kappa$ index, which combines the ease of calculation and the evaluation of the results at a statistical level, finding a $\kappa$ of 0.833 (Table 1).

Table 2 shows that the instrument was evaluated using the splithalf test that compares the correlations between the two halves of an instrument, and the reliability of the instrument was evaluated using the Cronbach's $\alpha$ to measure the degree of internal correlation between the items. Finding a quite adequate coefficient of reliability of 0.7 is satisfactory for the purposes of this investigation. When the item scale correlations were tested, the entire validity of the instrument was evaluated using the canonical correlation and

Table 1: Content validity of POCTOIR-30 (interpretation Landis and Koch)

\begin{tabular}{ll}
\hline$\kappa$ value & Interpretation \\
\hline$<0.00$ & Poor \\
$0.00-0.20$ & Slight \\
$0.21-0.40$ & Fair \\
$0.41-0.60$ & Moderate \\
$0.61-0.80$ & Substantial \\
$0.81-1.00$ & Almost perfect \\
\hline
\end{tabular}

The value was $0.833 ; p=0.000$. Demonstrating an almost perfect agreement for the content validity of the POCTOIR-30, having sufficient reliability

Table 2: Test-retest reliability and internal consistency of POCTOIR-30

\begin{tabular}{|c|c|c|c|c|}
\hline \multirow[b]{2}{*}{ Items } & \multirow[b]{2}{*}{ No. of items } & \multicolumn{2}{|c|}{ Test-retest reliability } & \multirow{2}{*}{$\begin{array}{l}\text { Internal } \\
\text { consistency }\end{array}$} \\
\hline & & ICC & $\begin{array}{l}\text { Confidence } \\
\text { intervals }\end{array}$ & \\
\hline Total score & 30 & 0.741 & $0.448-0.750$ & 0.738 \\
\hline
\end{tabular}

the intraclass correlation coefficient that measures the constancy of the responses obtained repeatedly with the same subjects.

Factorial analysis was performed on each of the 30 questions in the totality of subjects evaluated. Initially 7 dimensions or factors were identified, after evaluating the significance, 3 dimensions were discarded. The process of statistical readjustment showed that there should be 30 items grouped into 4 dimensions or factors: factor 1 : logistics and infrastructure; factor 2: training in oral implantology; factor 3: information about the graduate program; factor 4: future goals (Table 3 ).

The exploratory analysis was carried out through the descriptive statistics of the data, implying application of a series of measurements; depending on the type of each variable, it is important to know the values of central tendency and dispersion for each one of the questions of the questionnaire to be validated. All these explorations help us to detect possible errors in data entry, or data that can be very extreme and that would affect future calculations (Table 4).

\section{Discussion}

According to the results obtained, POCTOIR-30 has an excellent psychometric property. The POCTOIR-30 consists of four factors that focus on factor 1: logistics and Infrastructure; factor 2: training in oral implantology; factor 3: information about the graduate program; factor 4: future goals, our results are consistent with the results of many previous studies and recommendations, ${ }^{6-9}$ but diverge in terms of measuring the perception of postgraduate residents. ${ }^{14-16}$

This research suggests that by validating the questionnaire (POCTOIR-30), through the evaluation of the psychometric properties (content validity, factorial analysis and reliability) of the questionnaire developed to assess the perception of current training and future goals in oral implantology of postgraduate residents in stomatology in Peru. First, in order to validate the appropriate content of the questions in the POCTOIR-30 questionnaire, it was evaluated using the kappa coefficient, based on the criteria of 10 qualified judges, experts in the field who expressed their comments, suggestions based on relevance of the items. with the construction evaluated. ${ }^{14-17}$

In relation to reliability, Cronbach's $\alpha$ has shown an acceptable internal consistency, having an $\alpha$ of 0.7 , which is an adequate index. Aiken states that a fairly modest reliability coefficient of $0.60-0.70$ can be satisfactory for the purposes of an investigation when carried out in groups.

In general terms, despite having realized the psychometric properties of the POCTOIR-30 questionnaire, it is necessary to encourage future researchers to deepen the study using the present instrument in the multiple oral implantology specialties that are dictated nationally in different universities. For example, a study conducted by Huebner in 2002 showed that the intense exposure to oral implantology during training was reflected in a greater significant participation of implants in general practice dentistry. ${ }^{17,18}$ As more are trained in implant placement, more patients can receive implants. Finally, this study offers the dental community an instrument that is used in the exploration of the perception of current training and future goals in oral implantology of residents in Peru.

The main limitation of this study was that it was executed only in a private university in Peru; therefore, its intercultural validation is necessary to generalize about other countries. Another limitation is that this POCTOIR-30 questionnaire is only aimed at postgraduate 
Table 3: Exploratory factor analysis of the POCTOIR-30

\begin{tabular}{|c|c|c|c|c|}
\hline POCTOIR-30 items & Factor 1 & Factor 2 & Factor 3 & Factor 4 \\
\hline P1. The facilities of the university create an ideal environment & 0.280 & 0.713 & -0.591 & 0.249 \\
\hline P2. The equipment allows the development of surgical and/or prosthetic skills & 0.205 & 0.821 & 0.384 & -0.111 \\
\hline P3. Electronic information systems help to have access to knowledge & 0.212 & 0.431 & 0.300 & 0.338 \\
\hline P4. Administrative and/or academic staff provide the facilities to perform clinical activities & -0.016 & 0.403 & 0.062 & 0.0419 \\
\hline P5. The dental laboratory allows to perform clinical practices effectively & 0.161 & 0.489 & 0.331 & -0.078 \\
\hline P6. The learning of the techniques are those that are needed & 0.477 & 0.477 & 0.008 & 0.206 \\
\hline P7. The treatment with implants is more difficult & 0.402 & -0.141 & -0.450 & -0.078 \\
\hline P8. Consider that your curriculum provides the necessary courses & 0.569 & 0.133 & -0.200 & 0.206 \\
\hline P9. Oral implantology should be taught from undergraduate & 0.687 & 0.154 & -0.233 & -0.252 \\
\hline P10. The oral implantology is an area that must be covered sequentially & 0.996 & -0.081 & -0.003 & -0.083 \\
\hline P11. The resident must offer optimal training through simulation laboratories & 0.520 & -0.114 & 0.227 & -0.193 \\
\hline P12. Resident should use prerecorded video demonstrations and live demonstrations & 0.495 & 0.295 & -0.150 & -0.026 \\
\hline P13. Clinical cases should be distributed equally & 0.493 & -0.376 & 0.345 & -0.053 \\
\hline $\begin{array}{l}\text { P14. Competencies: professionalism, communication and interpersonal skills, information } \\
\text { management and critical thinking should be included as part of resident training }\end{array}$ & 0.593 & 0.202 & -0.229 & 0.751 \\
\hline $\begin{array}{l}\text { P15. Do you believe that there are advanced-level topics that are important for the development } \\
\text { of your life as a future specialist? }\end{array}$ & 0.440 & 0.006 & 0.174 & 0.117 \\
\hline P16. The residence must involve an international rotation & 0.202 & 0.186 & 0.462 & -0.279 \\
\hline P17. Oral implantology should only be taught at an accredited university & -0.025 & 0.234 & 0.498 & 0.467 \\
\hline P18. The residentado should offer a flexibility of time & 0.436 & -0.099 & 0.505 & 0.169 \\
\hline $\begin{array}{l}\text { P19. The program should perceive an environment of trust, freedom, and responsibility } \\
\text { with minimal rules, but very clear and rational }\end{array}$ & 0.654 & -0.227 & 0.611 & 0.042 \\
\hline P20. There must be direct supervision of implant placement & 0.011 & 0.016 & 0.503 & -0.000 \\
\hline P21. The curriculum exceeded your expectations & 0.174 & -0.054 & 0.439 & 0.000 \\
\hline P22. The dominance of some other language can affect the learning & -0.533 & 0.001 & 0.732 & -0.000 \\
\hline P23. Insufficient preparation of computer programs can affect learning & -0.361 & 0.421 & 0.662 & -0.308 \\
\hline P24. Do you believe that the cost of studying can influence the decision to study a graduate & -0.164 & 0.242 & 0.410 & 0.306 \\
\hline P25. During his residency, a climate of teamwork was perceived & 0.142 & -0.045 & 0.536 & 0.044 \\
\hline P26. Working conditions will improve after postgraduate studies & -0.019 & 0.135 & 0.456 & 0.223 \\
\hline P27. I will have greater competences for the development of research activities & 0.327 & 0.102 & 0.234 & 0.555 \\
\hline P28. I will be able to dedicate myself to teaching or other academic activities & -0.003 & 0.239 & 0.371 & 0.400 \\
\hline P29. There is a great respect for the best academics & 0.253 & 0.001 & 0.332 & 0.602 \\
\hline $\begin{array}{l}\text { P30. The completion of the residency will allow me to use concrete experience and reflective } \\
\text { observation in my future academic and clinical work }\end{array}$ & 0.139 & -0.411 & 0.115 & 0.430 \\
\hline
\end{tabular}

The bold values refer to the factor loadings of items. Factor loadings $>0.40$ were considered significant in this study

Tabe 4: Descriptive statistics of the questionnaire (POCTOIR-30)

\begin{tabular}{|c|c|c|c|c|c|}
\hline Dimension & Question & Mean & $S D$ & Min & Max \\
\hline \multirow{5}{*}{$\begin{array}{l}\text { Logistic and } \\
\text { infrastructure }\end{array}$} & P1. The facilities of the university create an ideal environment & 3.5 & 0.9 & 2 & 5 \\
\hline & P2. The equipment allows the development of surgical and/or prosthetic skills & 3.6 & 0.9 & 2 & 5 \\
\hline & P3. Electronic information systems help to have access to knowledge & 3.2 & 1.2 & 1 & 5 \\
\hline & $\begin{array}{l}\text { P4. Administrative and/or academic staff provide the facilities to perform clinical } \\
\text { activities }\end{array}$ & 3.1 & 0.8 & 2 & 5 \\
\hline & P5. The dental laboratory allows to perform clinical practices effectively & 3.5 & 0.9 & 2 & 5 \\
\hline \multirow{5}{*}{$\begin{array}{l}\text { Training in oral } \\
\text { implantology }\end{array}$} & P6. The learning of the needed techniques & 3.6 & 0.1 & 1 & 4 \\
\hline & P7. The treatment with implants is more difficult & & 1.1 & 1 & 5 \\
\hline & P8. Consider that your curriculum provides the necessary courses & 3.4 & 1.0 & 1 & 5 \\
\hline & P9. Oral implantology should be taught from undergraduate & 4.1 & 1.1 & 1 & 5 \\
\hline & P10. The oral implantology is an area that must be covered sequentially & 4.6 & 0.4 & 4 & 5 \\
\hline
\end{tabular}


Contd...

\begin{tabular}{|c|c|c|c|c|c|}
\hline Dimension & Question & Mean & $S D$ & Min & Max \\
\hline & P11. The resident must offer optimal training through simulation laboratories & 4.5 & 0.6 & 3 & 5 \\
\hline & P12. Resident should use prerecorded video demonstrations and live demonstrations & 4.5 & 0.6 & 3 & 5 \\
\hline & P13. Clinical cases should be distributed equally & 4.7 & 0.4 & 4 & 5 \\
\hline & $\begin{array}{l}\text { P14. Competencies: professionalism, communication and interpersonal skills, } \\
\text { information management and critical thinking should be included as part of } \\
\text { resident training }\end{array}$ & 4.5 & 0.7 & 2 & 5 \\
\hline & $\begin{array}{l}\text { P15. Do you believe that there are advanced-level topics that are important for the } \\
\text { development of your life as a future specialist? }\end{array}$ & 4.5 & 0.6 & 3 & 5 \\
\hline \multirow{11}{*}{$\begin{array}{l}\text { Information about the } \\
\text { graduate program }\end{array}$} & P16. The residence must involve an international rotation & 3.8 & 1.1 & 1 & 5 \\
\hline & P17. Oral implantology should only be taught at an accredited university & 4.2 & 1.1 & 1 & 5 \\
\hline & P18. The residentado should offer a flexibility of time & 4.0 & 0.8 & 1 & 5 \\
\hline & $\begin{array}{l}\text { P19. The program should perceive an environment of trust, freedom, and } \\
\text { responsibility with minimal rules, but very clear and rational }\end{array}$ & & & & \\
\hline & & 4.5 & 0.6 & 3 & 5 \\
\hline & P20. There must be direct supervision of implant placement & 4.1 & 0.9 & 2 & 5 \\
\hline & P21. The curriculum exceeded your expectations & 3.6 & 0.9 & 2 & 5 \\
\hline & P22. The dominance of some other language can affect the learning & 4.4 & 0.7 & 2 & 5 \\
\hline & P23. Insufficient preparation of computer programs can affect learning & 4.1 & 0.8 & 2 & 5 \\
\hline & $\begin{array}{l}\text { P24. Do you believe that the cost of studying can influence the decision to study a } \\
\text { graduate }\end{array}$ & 4.3 & 0.6 & 3 & 5 \\
\hline & P25. During his residency, a climate of teamwork was perceived & 3.7 & 0.9 & 2 & 5 \\
\hline \multirow{5}{*}{$\begin{array}{l}\text { Future goals after } \\
\text { postgraduate studies }\end{array}$} & P26. Working conditions will improve after postgraduate studies & 4.0 & 0.7 & 2 & 5 \\
\hline & P27. I will have greater competences for the development of research activities & 4.2 & 0.5 & 3 & 5 \\
\hline & P28. I will be able to dedicate myself to teaching or other academic activities & 3.9 & 0.8 & 2 & 5 \\
\hline & P29. There is a great respect for the best academics & 3.7 & 0.7 & 2 & 5 \\
\hline & $\begin{array}{l}\text { P30. The completion of the residency will allow me to use concrete experience and } \\
\text { reflective observation in my future academic and clinical work }\end{array}$ & 4.4 & 0.5 & 4 & 5 \\
\hline
\end{tabular}

professionals, especially in the area of oral implantology, in which we emphasize as a basis and/or its subsequent modification for research in other specialties and careers. Finally, this research has the limitation that it was made in a pilot sample, but it opens a line of research in relation to this topic. We suggest that it is necessary to investigate more thoroughly in the postgraduate residents with this new instrument, conducting comparative studies in different parts at a national and international level. In addition, we suggest carrying out the same research that completes the process of statistical validation of a questionnaire in a larger population of residents to verify the consistency of the present pilot study.

\section{Conclusion}

This pilot study showed that the POCTOIR-30 instrument has adequate levels of validity of content, criteria, construct, and reliability to be used in residents of areas related to oral implantology.

\section{ACKNOWLedgments}

The authors thank the Universidad Peruana Cayetano Heredia, Universidad Nacional Mayor de San Marcos and the Universidad
Científica del Sur, for their support in the constant training on topics of research methodology and statistics, in addition to providing guidelines for publishing in indexed journals.

\section{References}

1. Weintraub AM, Seckinger $R$, et al. Predoctoral implant dentistry programs in US dental schools. J Prosthodont 1995;4(2):116-121. DOI: 10.1111/j.1532-849X.1995.tb00326.x.

2. Seckinger RJ, Weintraub AM, et al. The status of undergraduate implant education in dental schools outside the United States. Implant Dent 1995;4(2):105-109. DOI: 10.1097/00008505-19950500000005.

3. Bell FA, Hendricson WD. A problem-based course in dental implantology. J Dent Educ 1993;57(9):687-695.

4. Schnitman P. Education in implant dentistry. J Am Dent Assoc 1990;121(3):330-332. DOI: 10.14219/jada.archive.1990.0176.

5. Simons AM, Bell FA, et al. Undergraduate education in implant dentistry. Implant Dent 1995;4(1):40-43. DOI: 10.1097/00008505199504000-00006.

6. Ismail JY. Predoctoral curriculum guidelines in implant dentistry. Int J Oral Implantol 1990;7(1):67-69.

7. Lim MV, Afsharzand Z, et al. Predoctoral implant education in U.S. dental schools. J Prosthodont 2005;14(1):46-56. DOI: 10.1111/j.1532849X.2004.04047.x. 
8. Afsharzand Z, Lim MV, et al. Predoctoral implant dentistry curriculum survey: European dental schools. Eur J Dent Educ 2005;9(1):37-45. DOI: 10.1111/j.1600-0579.2004.00363.x.

9. Klokkevold PR. Implant education in the dental curriculum. J Calif Dent Assoc 2001;29(11):747-755.

10. Wilcox CW, Huebner GR, et al. Placement and restoration of implants by predoctoral students: the Creighton experience. J Prosthodont 1997;6(1):61-65. DOI: 10.1111/j.1532-849X.1997. tb00066.x.

11. Maalhagh-Fard A, Nimmo A, et al. Implant dentistry in predoctoral education: the elective approach. J Prosthodont 2002;11(3):202-207. DOI: 10.1053/jopr.2002.126726.

12. Huebner GR. Evaluation of a predoctoral implant curriculum: does such a program influence graduates' practice patterns? Int J Oral Maxillofac Implants 2002;17(4):543-549.

13. Kido H, Yamamoto K, et al. Students' opinion of a predoctoral implant training program. J Dent Educ 2009;73(11):1279-1285.
14. Petropoulos VC, Arbree NS, et al. Teaching implant dentistry in the predoctoral curriculum: a report from the ADEA Implant Workshop's survey of deans. J Dent Educ 2006;70(5):580-588.

15. Maalhagh-Fard A, Nimmo A. Eleven-year report on a predoctoral implant dentistry program. J Prosthodont 2008;17(1):64-68.

16. Melo MD, McGann G, et al. Survey of implant training in oral and maxillofacial surgery residency programs in the United States. J Oral Maxillofac Surg 2007;65(12):2554-2558. DOI: 10.1016/ j.joms.2007.06.685.

17. Wright RF, Dunlop RA, et al. A survey of program directors: trends, challenges, and mentoring in prosthodontics. Part 1. J Prosthodont 2008;17(1):69-75.

18. Sukotjo C, Arbree NS. Prosthodontic program directors' perceptions regarding implantplacement by prosthodontic residents: a 2004 survey conducted by the Educational Policy Subcommittee of the American College of Prosthodontists. J Prosthodont 2008;17(8): 662-668. DOI: 10.1111/j.1532-849X.2008.00350.x. 